\title{
Alterations of Colonic Contractility in an Interleukin-10 Knockout Mouse Model of Inflammatory Bowel Disease
}

\author{
Jae Hyung Park, ${ }^{1}$ Joong Goo Kwon, ${ }^{2}$ Sun Joo Kim, ${ }^{1}$ Dae Kyu Song, ${ }^{1}$ Seok Guen Lee, ${ }^{3}$ Eun Soo Kim, ${ }^{3}$ Kwang Bum Cho, ${ }^{3}$ \\ Byung Ik Jang, ${ }^{4}$ Dae Hwan Kim, ${ }^{4}$ Jeong-Im Sin, ${ }^{5}$ Tae Wan Kim, ${ }^{6 *}$ In Hwan Song ${ }^{7}$, and Kyung Sik Park ${ }^{3 *}$ \\ ${ }^{1}$ Department of Physiology, Keimyung University School of Medicine, Daegu, Korea; ${ }^{2}$ Department of Internal Medicine, Catholic University of \\ Daegu School of Medicine, Daegu, Korea; ' Department of Internal Medicine, Keimyung University School of Medicine, Daegu, Korea, \\ ${ }^{4}$ Department of Internal Medicine, Yeungnam University College of Medicine, Daegu, Korea; ${ }^{5}$ Department of Microbiology, Kangwon National \\ University School of Medicine, Chuncheon, Korea; ${ }^{6}$ Department of Veterinary Physiology, College of Veterinary Medicine, Kyungpook National \\ University, Daegu, Korea; and ${ }^{7}$ Department of Anatomy, Yeungnam University College of Medicine, Daegu, Korea
}

\section{Background/Aims}

Inflammatory bowel disease is commonly accompanied by colonic dysmotility and causes changes in intestinal smooth muscle contractility. In this study, colonic smooth muscle contractility in a chronic inflammatory condition was investigated using smooth muscle tissues prepared from interleukin-10 knockout $\left(\mathrm{IL}-10^{-l-}\right)$ mice.

\section{Methods}

Prepared smooth muscle sections were placed in an organ bath system. Cholinergic and nitrergic neuronal responses were observed using carbachol and electrical field stimulation with L-NG-nitroarginine methyl ester (L-NAME). The expression of interstitial cells of Cajal (ICC) networks, muscarinic receptors, neuronal nitric oxide synthase (nNOS) and inducible nitric oxide synthase (iNOS) was observed via immunofluorescent staining.

\section{Results}

The spontaneous contractility and expression of ICC networks in the proximal and distal colon was significantly decreased in $\mathrm{IL}-10^{-1-}$ mice compared to $\mathrm{IL}-10^{+/+}$mice. The contractility in response to carbachol was significantly decreased in the proximal colon of $\mathrm{IL}-10^{-1-}$ mice compared to $\mathrm{IL}-10^{+/+}$mice, but no significant difference was found in the distal colon. In addition, the expression of muscarinic receptor type 2 was reduced in the proximal colon of IL-10 $0^{-1-}$ mice. The nictric oxide-mediated relaxation after electrical field stimulation was significantly decreased in the proximal and distal colon of IL-10 ${ }^{-1-}$ mice. In inflamed colon, the expression of nNOS decreased, whereas the expression of iNOS increased.

Received: February 2, 2014 Revised: September 25, 2014 Accepted: September 27, 2014

(c) This is an Open Access article distributed under the terms of the Creative Commons Attribution Non-Commercial License (http://creativecommons. org/licenses/by-nc/3.0) which permits unrestricted non-commercial use, distribution, and reproduction in any medium, provided the original work is properly cited.

${ }^{*}$ Correspondence: Kyung Sik Park and Tae Wan Kim are equally responsible for this study. Kyung Sik Park, MD

Department of Internal Medicine, Dongsan Medical Center, 56, Dalseong-ro, Jung-gu, Daegu 700-712, Korea Tel: +82-53-250-7088, Fax: +82-53-250-7442, E-mail: seenae99@dsmc.or.kr

Tae Wan Kim, DVM, PhD

Department of Veterinary Physiology, College of Veterinary Medicine, Kyungpook National University, 80, Daehak-ro, Buk-gu, Daegu 702-701, Korea

Tel: +82-53-950-7791, Fax: +82-53-950-5955, E-mail: twkim@mail.knu.ac.kr

Jae Hyung Park and Joong Goo Kwon equally contributed to this work.

Financial support: This study was supported by a grant (year 2008) from the Korean Society of Neurogastroenterology and Motility, Seoul, Korea and this research also supported by Basic Science Research Program through the National Research Foundation of Korea(NRF) funded by the Ministry of Education, Science, and Technology (NRF- 2012R1A1A4A01015288).

Conflicts of interest: None.

Author contributions: Jae Hyung Park, Seok Guen Lee, Joong Goo Kwon, Sun Joo Kim, Jeong-Im Sin, and In Hwan Song: basic experiment; Dae Kyu Song, Eun Soo Kim, and Kwang Bum Cho: searching and analysis of research data; Byung Ik Jang and Dae Hwan Kim: taking care of research animal and data analysis; Kyung Sik Park and Tae Wan Kim, plan and managment of experiment.

ORCID: Kyung Sik Park, http://orcid.org/0000-0003-1874-9936; Tae Wan Kim, http://orcid.org/0000-0002-7943-4682. 


\section{Conclusions}

These results suggest that damage to the ICC network and NOS system in the proximal and distal colon, as well as damage to the smooth muscle cholinergic receptor in the proximal colon may play an important role in the dysmotility of the inflamed colon.

(J Neurogastroenterol Motil 2015;21:51-61)

Key Words

Colon; Contractility; Inflammatory bowel diseases; Interleukin-10

\section{Introduction}

Inflammatory bowel disease (IBD) is a chronic disorder involving the digestive tract and is characterized by recurrent inflammation. ${ }^{1}$ IBD includes all diseases that cause chronic intestinal inflammation in a broad perspective, but it is generally divided into ulcerative colitis and Crohn's disease. The pathogenesis of both of these diseases remains unclear. ${ }^{1}$ Unlike ulcerative colitis that is restricted to the colon and invades the mucosa and submucosa, Crohn's disease can invade any part of the digestive tract transmurally from mucosa to serosa, thereby causing more diverse symptoms. ${ }^{1}$ Depending on the site and severity of inflammation, various bowel symptoms such as melena, abdominal pain and diarrhea, or systemic symptoms such as malabsorption, weight loss and fever may occur. Although bowel symptoms may occur due to injury of the mucosa or submucosa, they might also be caused by a functional abnormality of smooth muscle motility. Indeed, altered function of the intestinal neuromuscular apparatus as a result of previous or ongoing inflammatory events has been proposed as a mechanism of functional gastrointestinal disorders. ${ }^{2}$ In this aspect, inflammatory responses in IBD patients might also cause alterations in the morphology and function of enteric nerves, the interstitial cells of Cajal (ICC), and smooth muscle cells. This dysfunction may occur not only during the inflammatory episode but also during periods of remission. ${ }^{3}$ However, it is difficult to measure or investigate intestinal motility in IBD patients, therefore, most studies have been conducted using animal models.

Various animal models have been developed to study IBD. Models which spontaneously develop IBD include the $\mathrm{C} 3 \mathrm{H} /$ HeJBir mouse model, ${ }^{4}$ the cotton-top tamarins monkey model ${ }^{5}$ and the SAMP-I/Yit mouse model, ${ }^{6}$ whereas chemical-induced colitis models include the acetic acid-induced model, ${ }^{7}$ the trinitrobenzene sulfonic acid (TNBS)-induced model, ${ }^{8}$ the dextran sulfate sodium (DSS)-induced model, ${ }^{9}$ the peptidoglycan-poly- saccharide (PG-PS)-induced model ${ }^{10}$ and the indomethacin-induced model. ${ }^{11}$ Additionally, various genetically manipulated animal models have been developed, ${ }^{12}$ including the interleukin-10 (IL-10) knockout mouse model (IL-10 ${ }^{-/-}$). ${ }^{13}$

IL-10 is one of the anti-inflammatory cytokines that are produced in monocytes or lymphocytes and is known to inhibit cytokine synthesis in humans. IL-10 inhibits NF- $\mathrm{KB}$ activation and regulates Janus kinase signal transducers and activators of transcription (JAK-STAT) signal transduction, resulting in an anti-inflammatory effect through the inhibition of $\mathrm{T}$ helper 1 response and MHC class II antigen expression, the promotion of B-cell survival and proliferation and the facilitation of antibody formation. Thus, IL-10 is an essential factor in gastrointestinal tract immune regulation. In IL-10 $0^{-/-}$mice, the intestinal epithelial cell expression of HLA class II gene increases resulting in increased $\mathrm{T}$ helper 1 response and eventually causing inflammation. Inflammation initially occurs in response to intestinal microbial flora at age 7 weeks. ${ }^{12,13}$ The aforementioned IBD models demonstrate lesions similar to ulcerative colitis. In contrast, the IL- $10^{-/-}$mouse model demonstrates lesions similar to Crohn's disease with skip lesions in the cecum and proximal colon and a therapeutic response to anti-TNF- $\alpha$ treatment. ${ }^{14}$ Although many studies have been conducted to investigate digestive tract motility using various animal models, ${ }^{15-24}$ few studies have been conducted using IL-10 ${ }^{-1-}$ mice. Accordingly, this study was conducted to investigate changes in colonic contractility in IL-10 $0^{-/-}$mice and the possible mechanisms of these changes.

\section{Materials and Methods}

\section{Materials}

\section{IL-10 ${ }^{-/-}$mice}

Six IL-10 $0^{-1-}$ mice aged $20-30$ weeks and 6 C57BL/6J $\left(\mathrm{IL}-10^{+/+}\right.$) mice of the same age were used as the study and con- 
trol groups, respectively. The mice were provided by the animal laboratory of Yeungnam University College of Medicine. The study was conducted after approval by the Institutional Animal Care and Use Committee of Keimyung University College of Medicine. The mice were housed at $20 \pm 1^{\circ} \mathrm{C}$, and allowed to ingest water and foods freely. The light was turned on and off at 12-hour intervals.

\section{Genotyping}

The mice were bled for genotyping. Fifty microliters of blood was retro-orbitally obtained and was placed in a $1.5 \mathrm{~mL}$ microcentrifuge tube containing $10 \mu \mathrm{L}$ of $10 \mathrm{mM}$ EDTA, followed by treatment with the lysis buffers of the genomic DNA purification kit (ElpisBiotech, Daejon, Korea) in accordance with the manufacturer's protocol. The genomic DNA was reacted for $35 \mathrm{PCR}$ cycles $\left(94^{\circ} \mathrm{C}\right.$ for 30 seconds, $64^{\circ} \mathrm{C}$ for 1 minute, $72^{\circ} \mathrm{C}$ for $1 \mathrm{mi}-$ nute) with the 3 Jackson laboratory IL-10 genotype primers (wild type reverse primers, 5'-GTGGGTGCAGTTATTGTCTTCCCG-3'; common forward primers, 5'-GCCTTCAGTATAAAAGGGGGACC-3; mutant reverse primers, 5'-CCTGCGTGCAATCCATCTTG-3'). The final product was separated by gel electrophoresis on a $1 \%$ agarose gel. IL- $10^{-/-}$mice showed a DNA band at approximately 450 base pairs (bp) while wild type mice showed a DNA band at approximately 200 bp (Fig. 1).

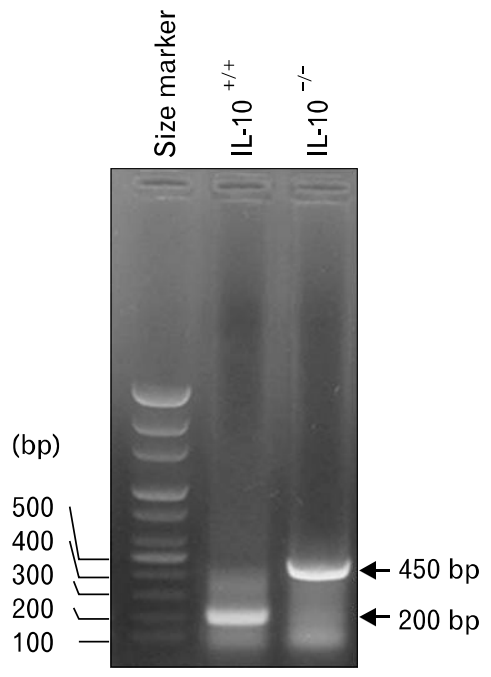

Figure 1. Genotyping. Interleukin-10 knockout (IL-10 ${ }^{-/-}$) mice show a DNA band at approximately 450 base pairs (bp) while wild type mice $\left(\mathrm{IL}-10^{+/+}\right.$) show a DNA band at approximately $200 \mathrm{bp}$.

\section{Contractility Measurement}

\section{Tissue preparation}

Mice were sacrificed by cervical dislocation and colonic segments $1.5 \mathrm{~cm}$ in length were collected from the proximal colon 1 $\mathrm{cm}$ distal to the cecum and from the distal colon $1 \mathrm{~cm}$ proximal to the anus. The segments were suspended in a $10 \mathrm{~mL}$ organ bath containing oxygenated Kreb's solution (composition in mM: 120 $\mathrm{NaCl}, 4.6 \mathrm{KCl}, 2.5 \mathrm{CaCl}_{2}, 1.2 \mathrm{MgCl}_{2}, 22 \mathrm{NaHCO}_{3}, 1.2$ $\mathrm{NaH}_{2} \mathrm{PO}_{4}$, and 11.5 glucose; oxygenated with $95 \% \mathrm{O}_{2}-5 \% \mathrm{CO}_{2}$; $\mathrm{pH}$ 7.4). The organ bath was maintained at $37 \pm 0.5^{\circ} \mathrm{C}$. Both ends of the segments were tied with thread. One end was attached to a tissue holder and the other end was connected to an isometric force transducer (FT-03; Grass Technology, Warwick, RI, USA). The signals from the force transducer were acquired by PowerLab 4/30 (ML866; AD Instruments, Colorado Springs, CO, USA) and were recorded and analyzed by LabChart 7 software (AD Instruments). An initial $0.5 \mathrm{~g}$ tension was loaded on the colonic segment.

After 1-hour of stabilization, drug treatment and electrical field stimulation (EFS) experiments were performed. During the stabilization period, Kreb's solution was replaced at 10-minute intervals.

\section{Cholinergic responses}

For the observation of cholinergic nerve responses, carbachol (Sigma-Aldrich, St. Louis, MO, USA), an activator of the acetylcholine receptor, was used at concentrations of $10^{-9}, 10^{-8}$, $10^{-7}, 10^{-6.5}$, and $10^{-6} \mathrm{M}$. The area under the curve (AUC) at each concentration was calculated.

\section{Nitrergic responses}

For the observation of nitric oxide (NO)-mediated nerve responses, EFS and $100 \mu \mathrm{M}$ L-NG-nitroarginine methyl ester (L-NAME, Sigma-Aldrich) were used. For EFS, the segments were fixed between two electrodes that formed an electrical field. Electrical stimulations $(10 \mathrm{~Hz}, 120 \mathrm{~V}, 0.5 \mathrm{msec}$ for 30 seconds each) were generated using an S48 stimulating device (Grass Technology).

\section{Immunofluorescence}

For observation of the ICC networks, whole tissues were used. The whole tissues were fixed in $4 \%$ paraformaldehyde, and then washed for 5 minutes with phosphate-buffered saline (PBS, 
$\mathrm{pH}$ 7.4) with a $3 \%$ dehydroxide solution. For observation of muscarinic receptors and NOS, whole tissues were removed immediately without fixation and frozen quickly with 2-methylbutane and liquid nitrogen. Then, the tissues were cut into $5-\mu \mathrm{m}$ sections using a cryostat. The tissues were preincubated in blocking solution (Invitrogen, Carlsbad, CA, USA) for 30 minutes before being incubated with primary antibodies at room temperature. The primary antibodies used in the study were anti-c-KIT (Santa Cruz Biotechnology, CA, USA), anti-M (mAChRM $_{2}$; Abcam, Cambridge, England), anti-neuronal nitric oxide synthase (anti-nNOS, Abcam), and anti-inducible nitric oxide synthase (anti-iNOS; Abcam, Cambridge, England). After reaction with the primary antibodies for 90 minutes, non-specific binding was removed using PBS, and the tissues were reacted with secondary antibodies for 90 minutes. The secondary antibodies used were Alexa Fluor 488 goat anti-rabbit antibody (Invitrogen, Carlsbad, CA, USA) and Alexa Fluor 546 goat anti-mouse antibody (Invitrogen). After reaction with the secondary antibodies, non-specific binding was removed using PBS. For nucleus stain- ing, the tissues were reacted with 4,6-diamidino-2-phenylindole (DAPI) for 5 minutes and then mounted with slow fade Gold (Invitrogen), and covered with a slide glass. The immunostained tissues were observed by confocal laser scanning microscope (LSM 5 EXCITER; Carl Zeiss, Jena, Germany) using a C-Apochromat $\times 40$ objective. Confocal images shown are digital composites of $Z$-series scans of 30 optical sections $(1.0 \mu \mathrm{m})$ through a depth of full or partial thickness of musculature. Image analysis was completed with LSM 5 EXCITER software (Carl Zeiss). Quantification was performed with image analysis software (Carl Zeiss LSM Image Examiner version 4.2.0.121). Fluorescence was measured by a blinded examiner and presented as the percentage of fluorescent intensity.

\section{Statistical Methods}

Data were analyzed using a SPSS statistical package (version 18.0, SPSS Inc, IL, USA), and presented as mean \pm SEM. Student's t-test was conducted for testing significance. A $P$-value $<0.05$ was considered significant.
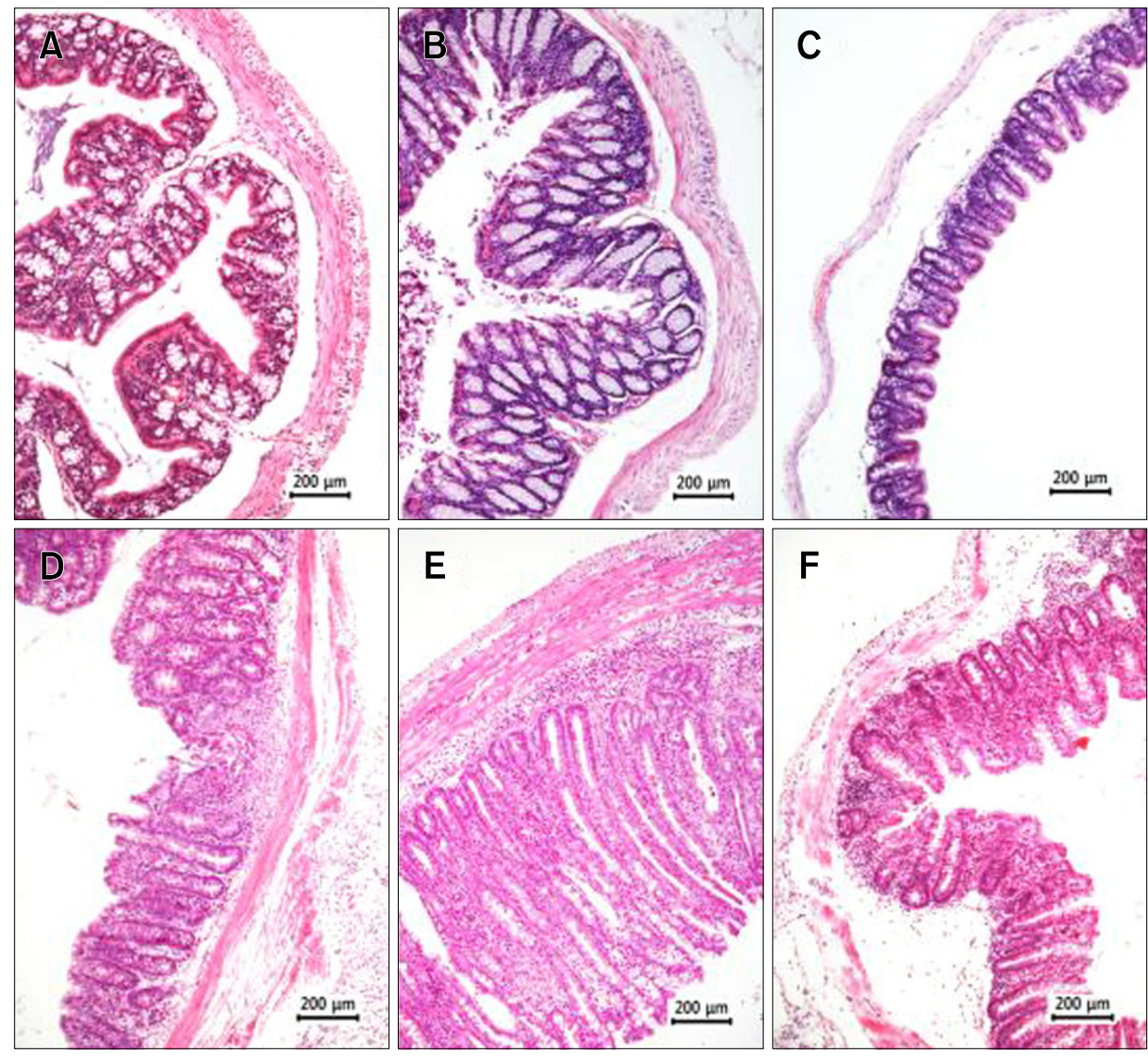

Figure 2. Histology. Micrographs of the ascending colon $(\mathrm{A}, \mathrm{D})$, descending colon $(\mathrm{B}, \mathrm{E})$, and cecum $(\mathrm{C}, \mathrm{F})$ of the interleukin-10 wild type (IL-10 $0^{+/+}$, A-C) and IL-10 knockout (IL-10 ${ }^{-/-}$) mice (D-F). Intestinal wall diameter and thickness are increased and advanced inflammatory changes are visible in IL- $10^{-/-}$mice. Inflammatory cells infiltrate all layers including the muscular layer and mucosal thickening is noted (H\&E stain, $\times 100)$. 
A IL-10 ${ }^{+/+}$ $\mathrm{IL}-10^{-/-}$

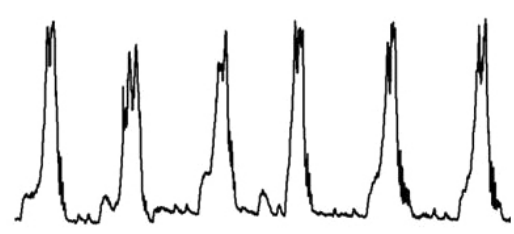

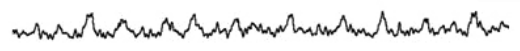

B

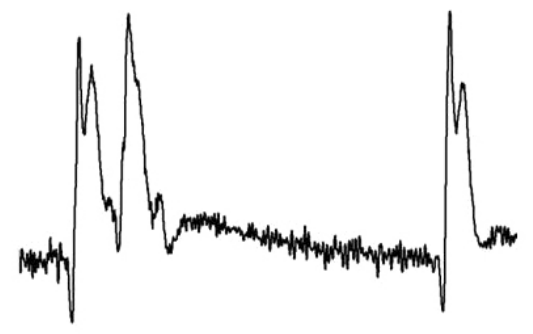

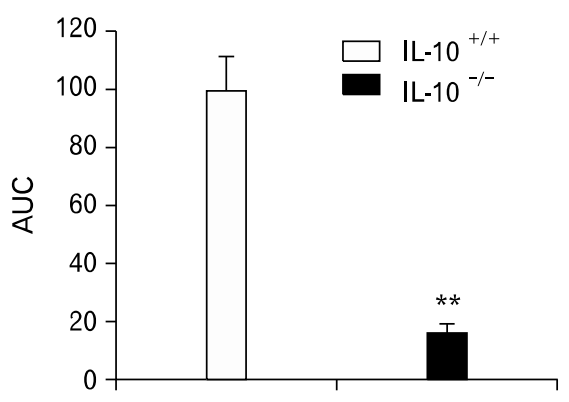

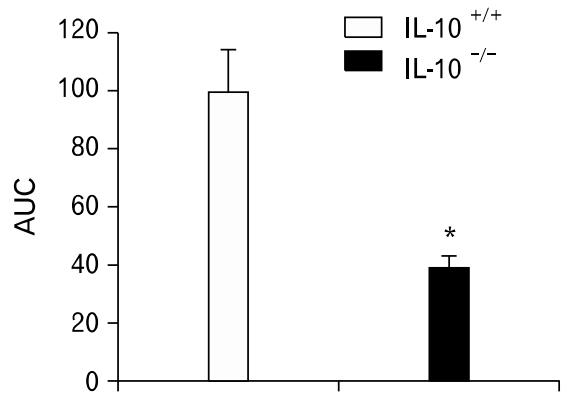

Figure 3. Spontaneous contractility of the proximal (A) and distal (B) colon in the interleukin-10 wild type (IL-10 ${ }^{+/+}$) and IL-10 knockout (IL-10 ${ }^{-/-}$) mice. The degree of contractility was expressed by area under the curve (AUC). Values are expressed as means \pm standard error of the mean $(n=6)$. ${ }^{*} P<0.05$ and ${ }^{* *} P<0.001$ compared to the IL-10 ${ }^{+/+}$.

\section{Results}

\section{Histology}

Hematoxylin and eosin staining revealed marked wall-thickening and advanced inflammatory changes in the cecum, ascending colon, and descending colon of IL-10 $0^{-1-}$ mice (Fig. 2) as had been previously reported in these mice. ${ }^{25}$

\section{Spontaneous Contractility}

The spontaneous contractility was significantly decreased in both the distal and proximal colon of IL- $10^{-/-}$mice compared with the IL-10 ${ }^{+/+}$mice (Fig. 3). When the contractile force was quantified using the AUC based on the basal line, the AUC for contractility significantly decreased in IL- $10^{-/-}$mice compared to the IL- $10^{+/+}$mice.

\section{Interstitial Cells of Cajal Networks}

ICC networks observed using anti-c-KIT antibody were well developed in the IL-10 ${ }^{+/+}$mice, but poorly developed in the proximal and distal colon of IL-10 ${ }^{-/-}$mice (Fig. 4).
A

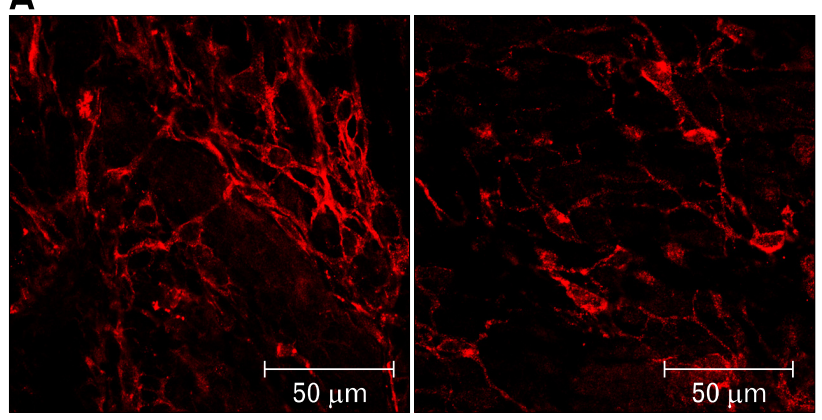

B

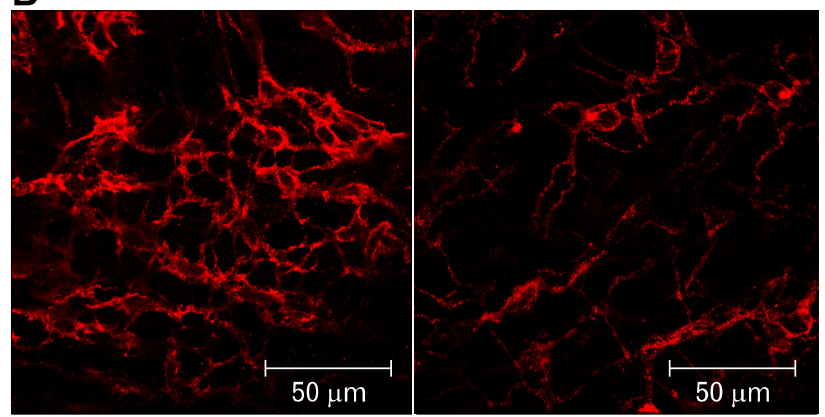

Figure 4. Networks of myenteric interstitial cells of Cajal of the proximal (A) and distal (B) colon in the interleukin-10 wild type $\left(\mathrm{IL}-10^{+/+}\right.$, left panel) and IL-10 knockout (IL-10 ${ }^{-/-}$, right panel) mice (×200). Immunofluorescence for anti-c-KIT is expressed as red color. 


\section{Cholinergic Response}

After carbachol treatment, the AUC for contraction response increased in a dosage-dependent manner in the proximal colon of the IL- $10^{+/+}$mice, but was significantly decreased in IL-10 ${ }^{-/-}$ mice (Fig. 5A). Meanwhile, no significant difference between

A

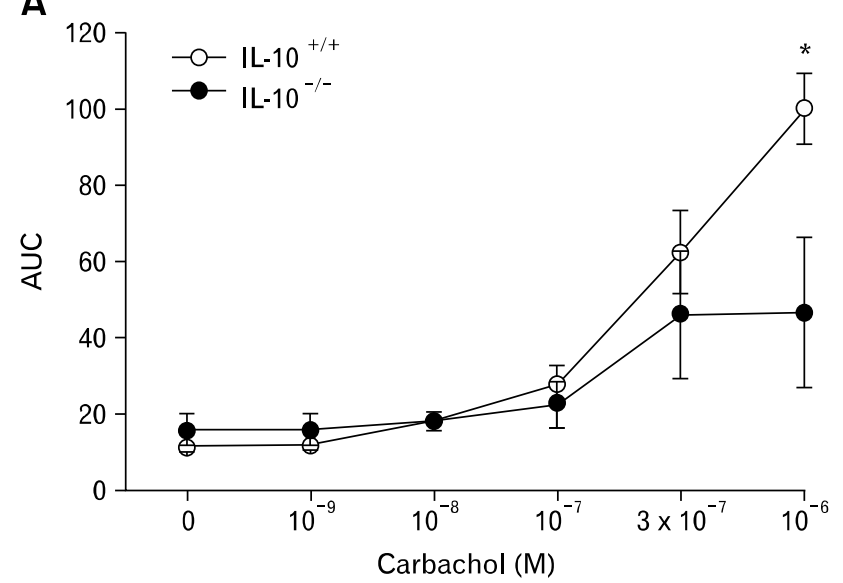

the 2 groups was found in the response to carbachol in the distal colon (Fig. 5B).

\section{Expression of Muscarinic Receptors}

Immunofluorescent staining of muscarinic type $2\left(\mathrm{M}_{2}\right)$ receptors showed that the expression of $\mathrm{M}_{2}$ receptors was reduced

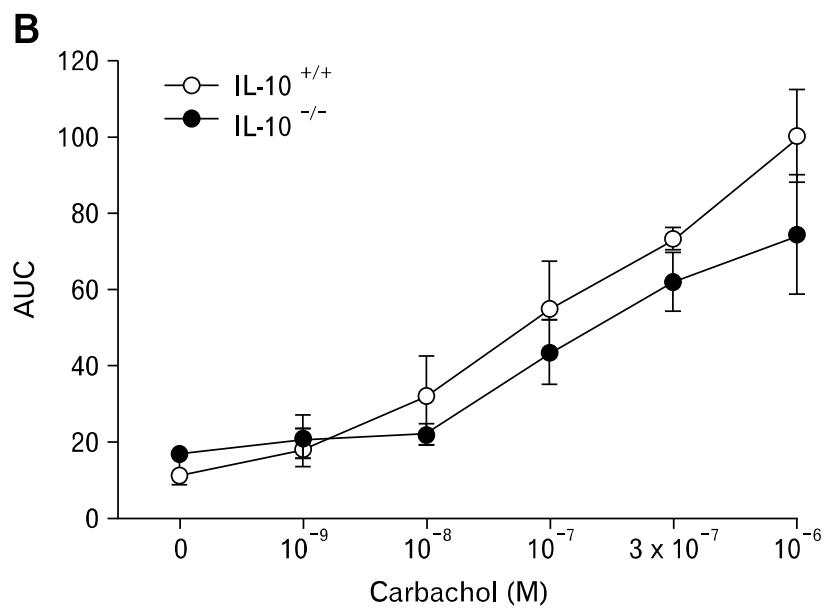

Figure 5. Effects of carbachol on contractility of the proximal (A) and distal (B) colon in interleukin-10 wild type (IL-10 ${ }^{+/+}$) and IL-10 knockout $\left(\mathrm{IL}-10^{-/-}\right)$mice $(\mathrm{n}=6)$. Values are expressed as means \pm standard error of the mean $(\mathrm{n}=6) .{ }^{*} \mathrm{P}<0.05$ compared to the IL-10 ${ }^{+/+}$.

A
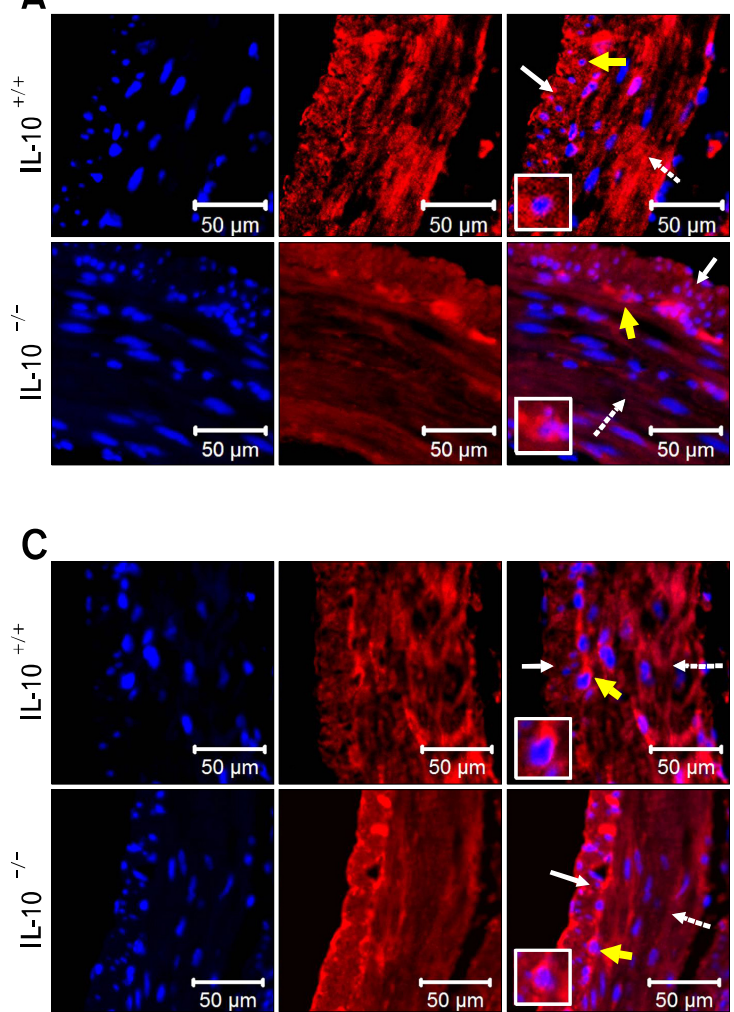

B

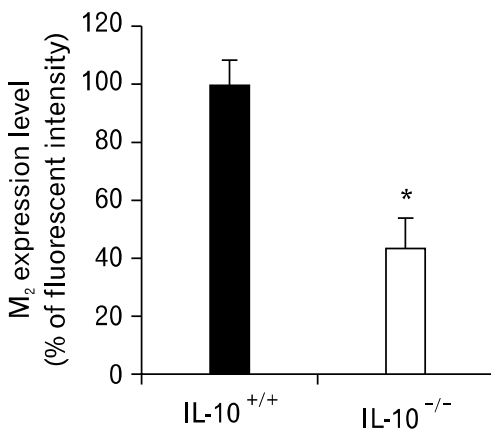

D

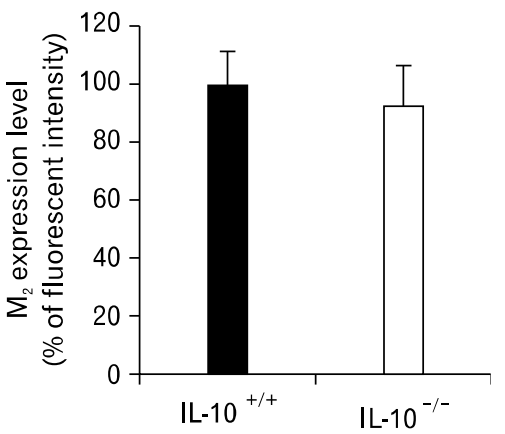

Figure 6. Expression of muscarinic receptor type 2 in the proximal (A) and distal (C) colon in interleukin-10 wild type (IL-10 $+/+$, upper panel) and IL-10 knockout (IL-10 ${ }^{-/-}$, lower panel) mice $(\times 400$; blue, nucleus and red, muscarinic receptor type $2\left[\mathrm{M}_{2}\right]$ ). The solid line arrow represents the outer longitudinal muscle layer; the dotted line arrow represents inner circular muscle layer; and the yellow line arrow represents cells in which $\mathrm{M}_{2}$ are expressed (representative data from $\mathrm{n}=5$ ). Relative $\mathrm{M}_{2}$ expression level in proximal (B) and distal (D) colon in IL- $10^{+/+}$and IL-10 ${ }^{-/-}$ mice. Values are expressed as the means \pm standard error of the mean $(\mathrm{n}=5) .{ }^{*} P$ $<0.05$ compared to the IL- $10^{+/+}$. 
in the proximal colon of IL-10 ${ }^{-1-}$ mice compared to the control mice (Fig. 6A and 6B). However, no difference in the expression of receptors was found in the distal colon between the 2 groups (Fig. 6C and 6D).

\section{Nitic Oxide-mediated Response}

During the 30 -second EFS, the proximal colon of the IL- $10^{+/+}$mice initially contracted, but then relaxed. Meanwhile, the proximal colon of IL-10 ${ }^{-/-}$mice continuously contracted without relaxation. When EFS was applied after treatment with atropine, an anticholinergic agent, a relaxation response occurred in the IL- $10^{+/+}$mice, but did not occur in IL- $10^{-/-}$mice (Fig. 7A). During 30-second EFS, the relaxation response occurred in the distal colon of the IL-10 ${ }^{+/+}$mice, and a similar response also occurred after atropine treatment. The contraction response also occurred in the distal colon of IL-10 $0^{-/-}$mice, but this response did not occur after atropine treatment (Fig. 7B). Relaxation immediately after contraction, which occurred in the proximal colon of the IL- $10^{+/+}$mice during EFS, was not observed after L-NAME treatment. No significant change was observed in IL-10 ${ }^{-1-}$ mice after L-NAME treatment (Fig. 8A). In con- trast, instead of relaxation which was observed in the distal colon of the IL- $10^{+/+}$mice during EFS, the contraction response was observed after L-NAME treatment. No significant change was observed in IL-10 $0^{-/-}$mice after L-NAME treatment (Fig. 8B).

\section{Nitric Oxide Synthase Expression}

Immunohistochemistry showed that the expression of nNOS was lower in both the proximal and distal colon of IL- $10^{-/-}$mice than in the IL- $10^{+/+}$mice, whereas the expression of NOS was higher in both regions in $\mathrm{IL}-10^{-/-}$mice than in the $\mathrm{IL}-10^{+/+}$ mice (Fig. 9).

\section{Discussion}

In this study, changes in colonic contractility and the underlying mechanisms of these changes were investigated in IL-10 mice with in vitro smooth muscle tension experiment and immunohistochemistry. We demonstrated that in IL-10 $0^{-/-}$mice colonic dysmotility was caused by damaged ICC networks and decreased nNOS expression in both the proximal and distal colon. Additionally, a decreased cholinergic response, caused by a
A

$\mathrm{IL}-10^{+/+}$

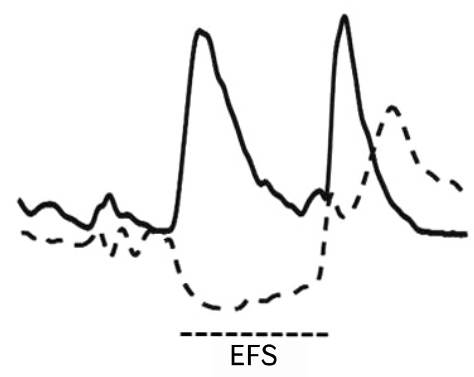

B

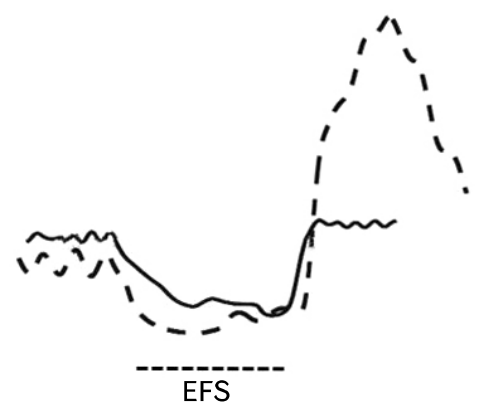

$\mathrm{IL}-10^{-/-}$
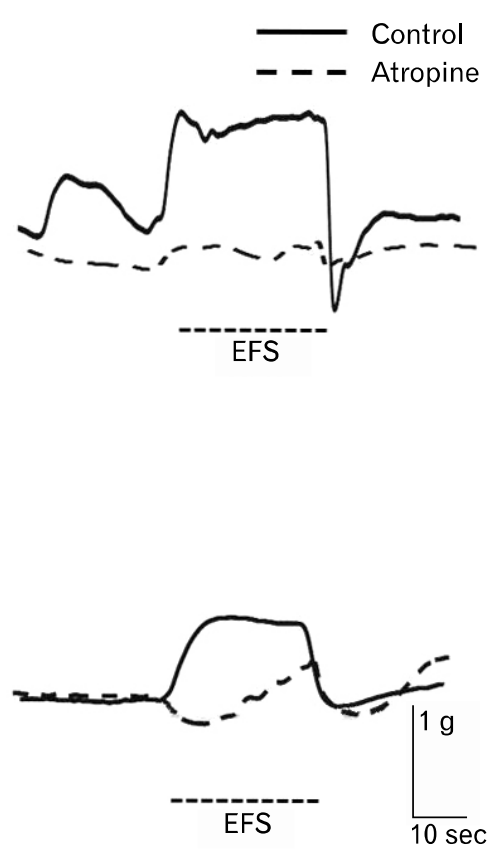

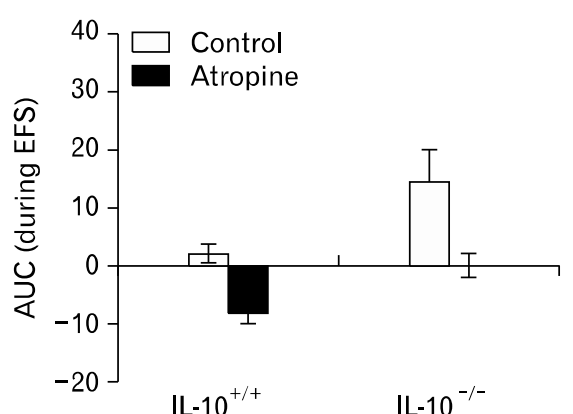

$\mathrm{IL}-10^{+/+}$ $\mathrm{IL}-10^{-/-}$

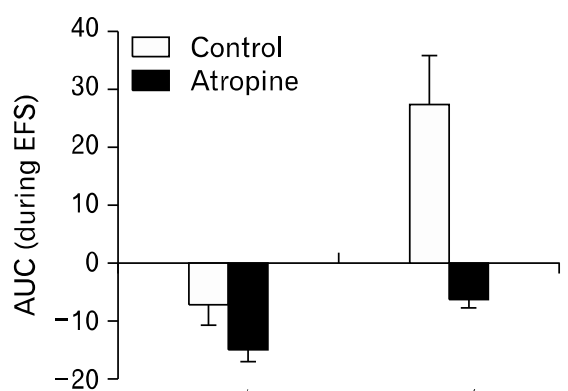

$\mathrm{IL}-10^{-1-}$

Figure 7. Response to electric field stimulation (EFS, $10 \mathrm{~Hz}$ ) of the proximal (A) and distal (B) colon in interleukin-10 wild type (IL-10 ${ }^{+/+}$) and IL-10 knockout $\left(\mathrm{IL}-10^{-/-}\right)$mice before and after treatment with atropine $(1 \mu \mathrm{M})$. Values are expressed as means \pm standard error of the mean $(\mathrm{n}$ $=6$ ). AUC, area under the curve. 
A

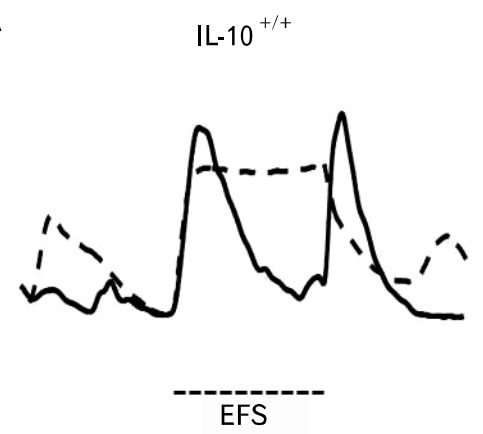

B

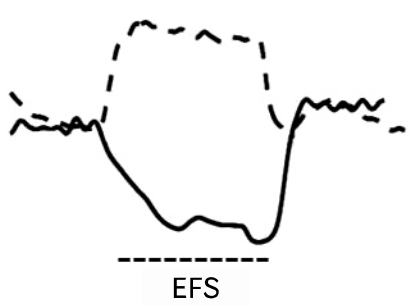

$\mathrm{IL}-10^{-/-}$
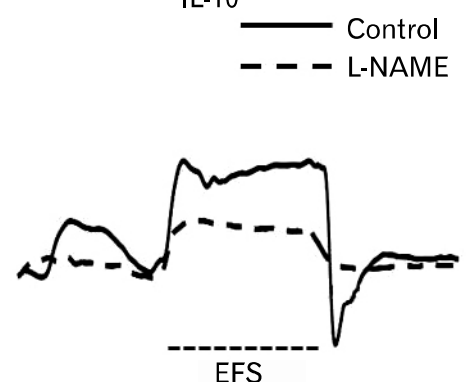

EFS

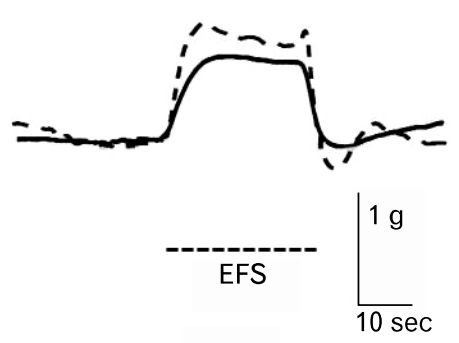

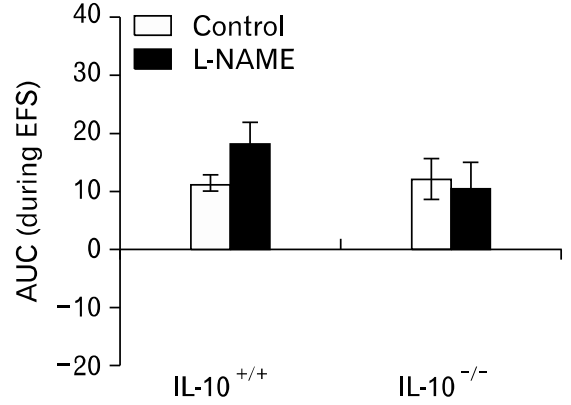

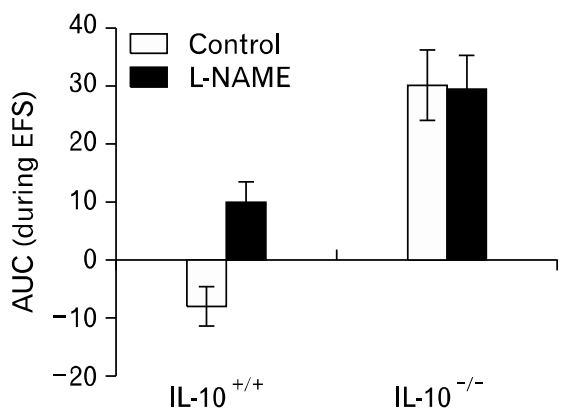

Figure 8. Response to electric field stimulation (EFS, $10 \mathrm{~Hz}$ ) of the proximal (A) and distal (B) colon in interleukin-10 wild type (IL-10 ${ }^{+/+}$) and IL-10 knockout (IL-10 ${ }^{-/-}$) mice before and after treatment with L-NG-nitroarginine methyl ester (L-NAME, $\left.100 \mu \mathrm{M}\right)$. Values are expressed as means \pm standard error of the mean $(n=6)$.

decreased expression of muscarinic receptors in the proximal colon, was noted in IL- $10^{-/-}$mice.

Gastrointestinal motility is controlled by spontaneous periodic contractions signaled by the ICC networks with excitatory and inhibitory responses. In this study, periodic spontaneous colonic motility was compared by observing the ICC networks in the IL- $10^{+/+}$and $\mathrm{IL}-10^{-/-}$mice using immunohistochemistry. Excitatory responses were induced with carbachol; and inhibitory responses were induced with EFS and L-NAME. Recently, the ICC, which is known to regulate spontaneous contraction by generating slow waves in the smooth muscle of the gastrointestinal tract, has been increasingly studied. ${ }^{17,26-36}$ Many studies have reported that ICC injury plays an important role in various chronic diseases that cause abnormal gastrointestinal contractions. ${ }^{27,29-33,35}$ In addition, it has been reported that spontaneous contraction signals are transmitted by ICC networks and that the loss of small intestinal motility in humans was caused by reduction in the ICC networks. ${ }^{37}$ Furthermore, gastrointestinal smooth muscle is spontaneously active with rhythmic generation of phasic contractions, triggered by ICC distributed in the gut wall. ${ }^{38}$ The results of this study show that spontaneous contractility and ICC expression are significantly lower in the proximal and distal colon of IL- $10^{-/-}$mice than in those of IL- $10^{+/+}$mice. Thus, it is likely that reductions in ICC expression and ICC network are the major causes for decreased spontaneous contraction in $\mathrm{IL}-10^{-/-}$ mice.

Excitatory responses are mainly regulated via acetylcholine receptors in the gastrointestinal tract. Carbachol is an agonist that stimulates acetylcholine receptors. Among muscarinic receptors, $\mathrm{M}_{2}$ and $\mathrm{M}_{3}$ receptors are mainly expressed in the gastrointestinal tract, and play an important role in the motility of the gastrointestinal tract. ${ }^{39,40}$ In this study, the contraction response increased in a dose-dependent fashion in the proximal and distal colon of IL- $10^{+/+}$mice after carbachol treatment while the contraction response to carbachol was significantly lower in the proximal colon of $\mathrm{IL}-10^{-/-}$mice compared to $\mathrm{IL}-10^{+/+}$mice. However, there was no difference in the contraction response to carbachol between the IL- $10^{+/+}$and IL- $10^{-/-}$mice in the distal colon. Additionally, the expression of $\mathrm{M}_{2}$ receptors measured immunohistochemically, was lower in the proximal colon of IL-10 ${ }^{-/-}$ mice than in the IL- $10^{+/+}$mice, but not significantly different in the distal colon. The decreased expression of muscarinic re- 
A

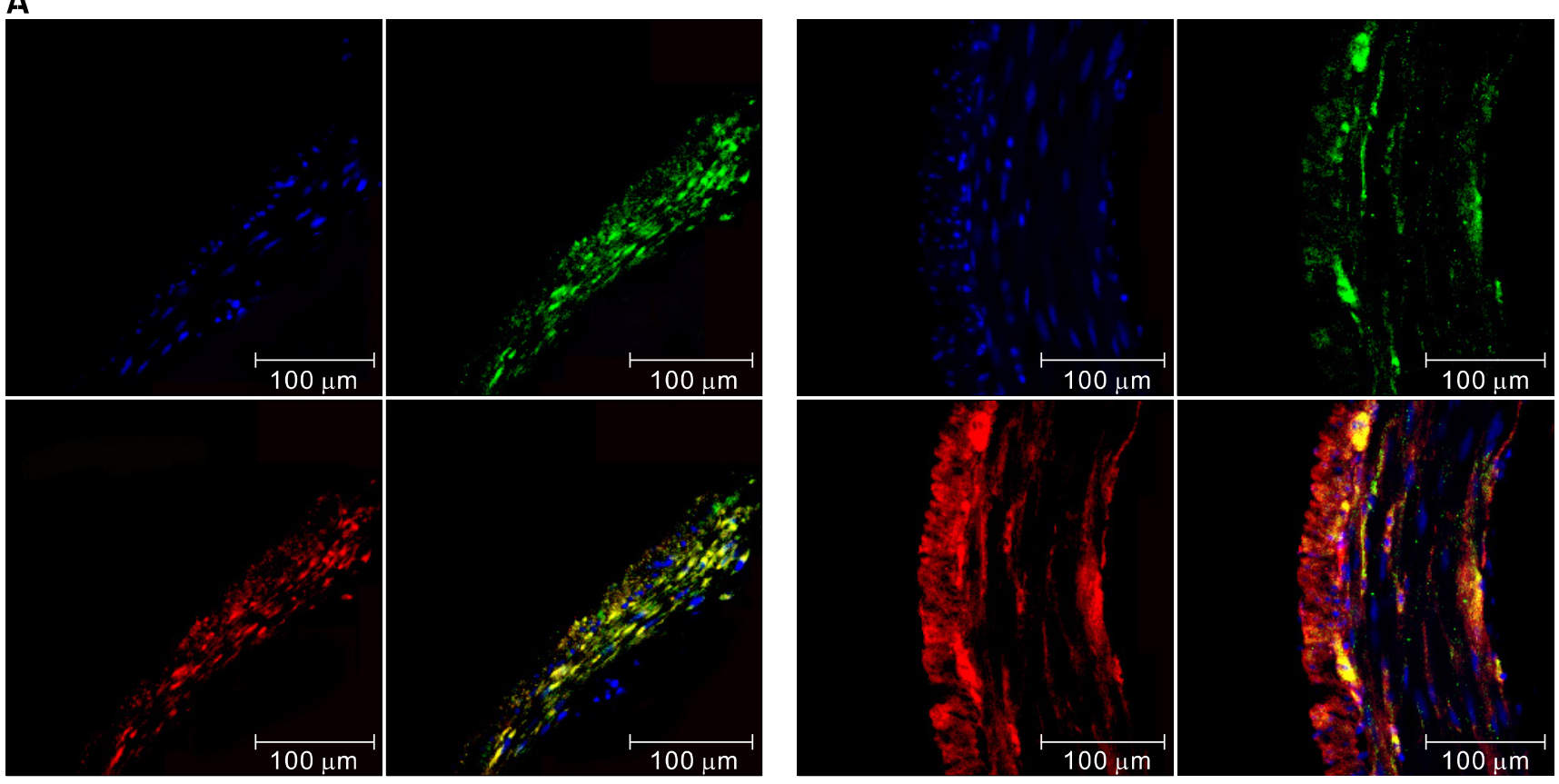

B

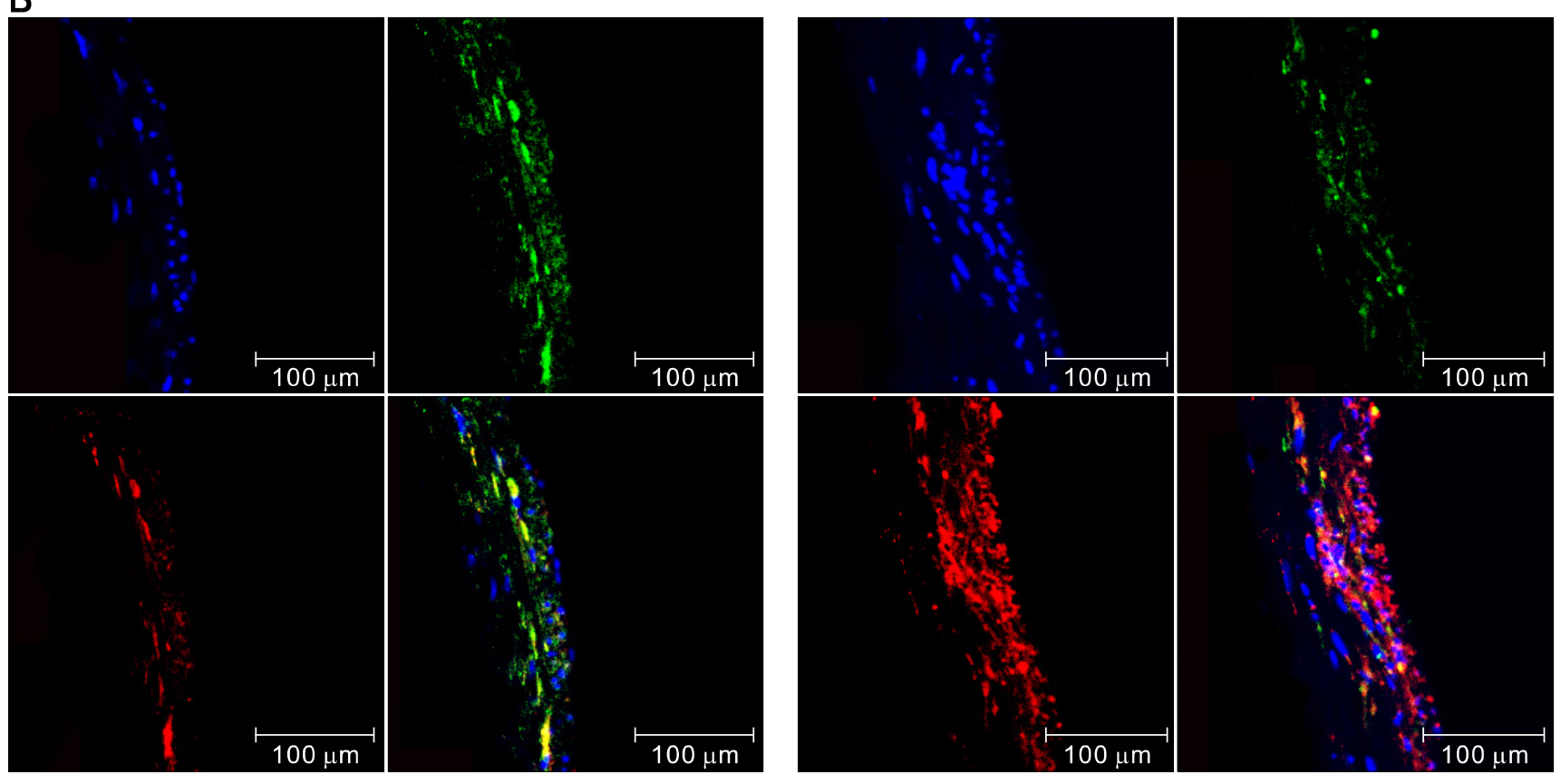

Figure 9. Expression of neuronal nitric oxide synthase (nNOS) and inducible nitric oxide synthase (iNOS) in the proximal (A) and distal (B) colon in interleukin-10 wild type (IL-10 $0^{+/+}$, left panel) and IL-10 knockout (IL-10 ${ }^{-/-}$, right panel) mice ( $\times 200$; blue, nucleus; green, nNOS; red, iNOS).

ceptors in the proximal colon likely results in decreased contractility of the proximal colon. Future studies of $\mathrm{M}_{3}$ receptor expression are necessary.

Relaxation responses in the colon are mainly regulated by NO-mediated nerves, and nNOS plays an important role in this response. ${ }^{41}$ Responses that occur when EFS is applied vary depending on animal type and the region of the gastrointestinal tract. It appears that the ultimate response is determined on the basis of which stimulus occurs first or which stimulus is stronger between cholinergic mediated contraction and NO-mediated 
relaxation. In this study, the proximal colon initially contracted and then relaxed in the IL- $10^{+/+}$mice during EFS. This indicates that cholinergic contraction initially occurred in the proximal colon, and that NO-mediated relaxation followed cholinergic contraction during EFS. Meanwhile, the proximal colon remained continuously contracted in IL- $10^{-/-}$mice without relaxation during EFS. This continuous contraction is likely attributable to the fact that $\mathrm{NO}$-mediated relaxation was more severely damaged than the cholinergic mediated response. When EFS was applied after atropine treatment, the relaxation response occurred in the IL- $10^{+/+}$mice during EFS, but did not occur in IL- $10^{-/-}$mice. This result also indicates the presence of damaged NO-mediated relaxation in the proximal colon of $\mathrm{IL}-10^{-/-}$ mice. On the other hand, in the distal colon, continuous relaxation occurred in the IL-10 $0^{+/+}$mice during EFS and a similar response was observed after atropine treatment. Thus, it is likely that NO-mediated relaxation predominates over cholinergic contraction in the normal distal colon. In IL- $10^{-/-}$mice, the contraction response occurred during EFS, but this response did not occur after atropine treatment. This result indicates that the NO-mediated relaxation response was also damaged in the distal colon of IL-10 ${ }^{-/-}$mice. L-NAME is known to suppress NO release. ${ }^{42}$ Thus, the degree of NO-mediated relaxation, induced by EFS, can be assessed by comparing responses to EFS before and after L-NAME treatment. In this study, relaxation immediately after contraction was observed in the proximal colon of the IL-10 ${ }^{+/+}$mice during EFS, but steady contraction without any relaxation was induced by EFS after L-NAME treatment. On the other hand, contraction with minimal relaxation continued during EFS even without L-NAME administration in the proximal colon of IL-10 $0^{-/-}$mice. Only relaxation was induced during EFS in the distal colon of the IL- $10^{+/+}$mice. However, continued contraction occurred instead of relaxation after L-NAME administration in the distal colon of the IL- $10^{+/+}$mice. This suggests that $\mathrm{NO}$ is the dominant neurotransmitter in the normal distal colon. However, in the distal colon of IL-10 ${ }^{-/-}$mice, only continuous contraction occurred during EFS even in the absence of any treatment. These data also suggest that nitrergic nerves are damaged in the proximal and distal colon of IL- $10^{-1-}$ mice.

It has been demonstrated that iNOS expression is high in the intestinal tract with severe inflammation. ${ }^{16,20,27,37}$ The results of this study are consistent with the results of these previous studies.

This study has several limitations. First, a small number of mice were used in the present study. Second, responses other than cholinergic and nitrergic, such as adrenergic or neurokininergic responses, were not controlled for in this study. Nevertheless, this study is meaningful because it was conducted using IL-10 mice, a model that resembles human Crohn's disease. Future larger studies are required based on the results of our study to further investigate the mechanisms of dysmotility in IBD and to evaluate potential therapies.

In conclusion, damage to the ICC networks and NOS system in the proximal and distal colon as well as the damage to smooth muscle cholinergic receptors in the proximal colon may play an important role in dysmotility of the inflamed colon.

\section{References}

1. Podolsky DK. Inflammatory bowel disease (1). N Engl J Med 1991;325:928-937.

2. Spiller RC. Inflammation as a basis for functional GI disorders. Best Pract Res Clin Gastroenterol 2004;18:641-661.

3. Geboes K, Collins S. Structural abnormalities of the nervous system in Crohn's disease and ulcerative colitis. Neurogastroenterol Motil 1998;10:189-202.

4. Sundberg JP, Elson CO, Bedigian H, Birkenmeier EH. Spontaneous, heritable colitis in a new substrain of $\mathrm{C} 3 \mathrm{H} / \mathrm{HeJ}$ mice. Gastroenterology 1994;107:1726-1735.

5. Madara JL, Podolsky DK, King NW, Sehgal PK, Moore R, Winter HS. Characterization of spontaneous colitis in cotton-top tamarins (Saguinus oedipus) and its response to sulfasalazine. Gastroenterology 1985;88(1 Pt 1):13-19.

6. Matsumoto $\mathrm{S}$, Okabe $\mathrm{Y}$, Setoyama $\mathrm{H}$, et al. Inflammatory bowel disease-like enteritis and caecitis in a senescence accelerated mouse P1/Yit strain. Gut 1998;43:71-78.

7. Sharon P, Stenson WF. Metabolism of arachidonic acid in acetic acid colitis in rats. Similarity to human inflammatory bowel disease. Gastroenterology 1985;88(1 Pt 1):55-63.

8. Morris GP, Beck PL, Herridge MS, Depew WT, Szewczuk MR, Wallace JL. Hapten-induced model of chronic inflammation and ulceration in the rat colon. Gastroenterology 1989;96:795-803.

9. Hirono I, Kuhara K, Hosaka S, Tomizawa S, Golberg L. Induction of intestinal tumors in rats by dextran sulfate sodium. J Natl Cancer Inst 1981;66:579-583.

10. Sartor RB, Bond TM, Schwab JH. Systemic uptake and intestinal inflammatory effects of luminal bacterial cell wall polymers in rats with acute colonic injury. Infect Immun 1988;56:2101-2108.

11. Yamada T, Deitch E, Specian RD, Perry MA, Sartor RB, Grisham MB. Mechanisms of acute and chronic intestinal inflammation induced by indomethacin. Inflammation 1993;17:641-662.

12. Jang BI. Animal models of inflammatory bowel disease. Intest Res 2008;6:8-18.

13. Kühn R, Löhler J, Rennick D, Rajewsky K, Müller W. Interleukin-10-deficient mice develop chronic enterocolitis. Cell 1993;75: 263-274.

14. Scheinin T, Butler DM, Salway F, Scallon B, Feldmann M. Validation of the interleukin-10 knockout mouse model of colitis: antitumour necrosis factor-antibodies suppress the progression of 
colitis. Clin Exp Immunol 2003;133:38-43.

15. Yoon SJ, Kim JH, Song DH, Lee YH, Park H, Lee SI. Changes in colonic transit and contractility of muscle according to the time course in TNBS-induced colitis. Korean J Neurogastroenterol Motil 2008;14:122-128.

16. Van Crombruggen K, Van Nassauw L, Demetter P, Cuvelier C, Timmermans JP, Lefebvre RA. Influence of soluble guanylate cyclase inhibition on inflammation and motility disturbances in DSSinduced colitis. Eur J Pharmacol 2008;579:337-349.

17. Auli M, Nasser $\mathrm{Y}, \mathrm{Ho} \mathrm{W}$, et al. Neuromuscular changes in a rat model of colitis. Auton Neurosci 2008;141:10-21.

18. Ohama T, Hori M, Ozaki H. Mechanism of abnormal intestinal motility in inflammatory bowel disease: how smooth muscle contraction is reduced? J Smooth Muscle Res 2007;43:43-54.

19. Tanović A, Fernández E, Jiménez M. Alterations in intestinal contractility during inflammation are caused by both smooth muscle damage and specific receptor-mediated mechanisms. Croat Med J 2006;47:318-326.

20. Kiyosue M, Fujisawa M, Kinoshita K, Hori M, Ozaki H. Different susceptibilities of spontaneous rhythmicity and myogenic contractility to intestinal muscularis inflammation in the hapten-induced colitis. Neurogastroenterol Motil 2006;18:1019-1030.

21. Piepoli AL, De Salvatore G, De Salvia MA, et al. Indomethacin-induced ileitis is associated with tensiometric, vascular and oxidative changes in the experimental rat model. Eur J Clin Invest 2005;35: 271-278

22. Park H, Ji SW, Lim JH, Lee SI. Altered colonic motor functions in experimental colitis of guinea pigs. Korean J Gastrointest Motil 2003;9:53-58.

23. Bossone C, Hosseini JM, Piñeiro-Carrero V, Shea-Donohue T. Alterations in spontaneous contractions in vitro after repeated inflammation of rat distal colon. Am J Physiol Gastrointest Liver Physiol 2001;280:G949-G957.

24. Myers BS, Martin JS, Dempsey DT, Parkman HP, Thomas RM, Ryan JP. Acute experimental colitis decreases colonic circular smooth muscle contractility in rats. Am J Physiol 1997;273(4 Pt 1):G928G936.

25. Hoshi N, Schenten D, Nish SA, et al. MyD88 signalling in colonic mononuclear phagocytes drives colitis in IL-10-deficient mice. Nat Commun 2012;3:1120.

26. Sanders KM, Hwang SJ, Ward SM. Neuroeffector apparatus in gastrointestinal smooth muscle organs. J Physiol 2010;588(Pt 23): 4621-4639.

27. Sanders KM, Koh SD, Ward SM. Interstitial cells of cajal as pacemakers in the gastrointestinal tract. Annu Rev Physiol 2006;68: 307-343.

28. Iwasaki H, Kajimura M, Osawa S, et al. A deficiency of gastric inter- stitial cells of Cajal accompanied by decreased expression of neuronal nitric oxide synthase and substance $\mathrm{P}$ in patients with type 2 diabetes mellitus. J Gastroenterol 2006;41:1076-1087.

29. Horváth VJ, Vittal H, Lörincz A, et al. Reduced stem cell factor links smooth myopathy and loss of interstitial cells of cajal in murine diabetic gastroparesis. Gastroenterology 2006;130:759-770.

30. Long QL, Fang DC, Shi HT, Luo YH. Gastro-electric dysrhythm and lack of gastric interstitial cells of cajal. World J Gastroenterol 2004;10:1227-1230.

31. Iino S, Ward SM, Sanders KM. Interstitial cells of Cajal are functionally innervated by excitatory motor neurones in the murine intestine. J Physiol 2004;55(Pt 2)6:521-530.

32. Horiguchi K, Sanders KM, Ward SM. Enteric motor neurons form synaptic-like junctions with interstitial cells of Cajal in the canine gastric antrum. Cell Tissue Res 2003;311:299-313.

33. Ward SM, Beckett EA, Wang X, Baker F, Khoyi M, Sanders KM. Interstitial cells of Cajal mediate cholinergic neurotransmission from enteric motor neurons. J Neurosci 2000;20:1393-1403.

34. Epperson A, Hatton WJ, Callaghan B, et al. Molecular markers expressed in cultured and freshly isolated interstitial cells of Cajal. Am J Physiol Cell Physiol 2000;279:C529-C539.

35. Ward SM, Morris G, Reese L, Wang XY, Sanders KM. Interstitial cells of Cajal mediate enteric inhibitory neurotransmission in the lower esophageal and pyloric sphincters. Gastroenterology 1998;115:314329.

36. Thuneberg L. Interstitial cells of Cajal: intestinal pacemaker cells? Adv Anat Embryol Cell Biol 1982;71:1-130.

37. Lee HT, Hennig GW, Fleming NW, et al. The mechanism and spread of pacemaker activity through myenteric interstitial cells of Cajal in human small intestine. Gastroenterology 2007;132:18521865 .

38. Sanders KM. A case for interstitial cells of Cajal as pacemakers and mediators of neurotransmission in the gastrointestinal tract. Gastroenterology 1996;111:492-515.

39. Suguro M, Matsuyama H, Tanahashi $Y$, et al. Muscarinic receptor subtypes mediating $\mathrm{Ca}^{2+}$ sensitization of intestinal smooth muscle contraction: studies with receptor knockout mice. J Vet Med Sci 2010;72:443-451.

40. Unno T, Matsuyama H, Izumi Y, Yamada M, Wess J, Komori S. Roles of $\mathrm{M}_{2}$ and $\mathrm{M}_{3}$ muscarinic receptors in cholinergic nerve-induced contractions in mouse ileum studied with receptor knockout mice. Br J Pharmacol 2006;149:1022-1030.

41. Sung TS, La JH, Kim TW, Yang IS. Alteration of nitrergic neuromuscular transmission as a result of acute experimental colitis in rat. J Vet Sci 2006; 7:143-150.

42. Mizuta Y, Takahashi T, Owyang C. Nitrergic regulation of colonic transit in rats. Am J Physiol 1999;277(2 Pt 1):G275-G279. 